\title{
Intravenous and oral amiodarone for arrhythmias in children
}

\author{
CLIFFORD A BUCKNALL, BARRY R KEETON, * PAUL V L CURRY, \\ MICHAEL J TYNAN, GEORGE R SUTHERLAND, „ DAVID W HOLT \\ From the Departments of Cardiology and Paediatric Cardiology, and the Poisons Unit, Guy's Hospital, \\ London, and ${ }^{\star}$ Wessex Cardiac Centre, Southampton General Hospital, Southampton
}

SUMMARY Oral amiodarone was administered to 30 children (aged one week to 14 years) for treatment of resistant or life threatening tachycardias. Five children received initial intravenous medication. The mean duration of oral treatment ranged from two weeks to 64 months (mean 23 months). Infants required a higher oral dose than older children when this was calculated on the basis of body weight but not when it was calculated on the basis of body surface area, indicating that the prescribed dose of amiodarone for infants should be calculated on the basis of body surface area. Although plasma concentrations of amiodarone were similar in infants and children, the plasma concentration of the metabolite desethylamiodarone was lower in infants. The arrhythmias were effectively controlled, by amiodarone alone in 19 and by amiodarone in combination with other drugs in nine children; amiodarone was ineffective in the remaining two children. Unwanted effects were common but were not significantly related to the dose, duration of treatment, or plasma concentration of amiodarone when group results were analysed. Grey facial skin pigmentation developed in two patients who received high cumulative doses of amiodarone and in whom plasma concentrations of amiodarone were high. Four children with biochemical hepatic dysfunction had high plasma concentrations of amiodarone and a further four children who experienced sleep disturbance had required high doses of amiodarone.

The antiarrhythmic properties of amiodarone were recognised soon after its introduction as an antianginal drug. Early experience showed the drug to be effective in children with cardiac arrhythmias ${ }^{1}$; amiodarone resulted in either complete control $(60 \%)$ or clinical improvement $(33 \%){ }^{1}$ The oral dosage and plasma concentrations of amiodarone associated with arrhythmia suppression in children have not been previously reported.

The unwanted effects experienced by adults receiving treatment with amiodarone ${ }^{23}$ have been reported to occur less commonly in children. In a study by Coumel and Fidelle, 135 children were treated with oral amiodarone for a mean of five months-three children had clinically apparent thyroid dysfunction, five had cutaneous photo-

Requests for reprints to Dr Clifford A Bucknall, Cardiac Department, King's College Hospital, Denmark Hill, London SE5 9RS.

Accepted for publication 21 April 1986 sensitivity, and grey pigmentation developed in one child. ${ }^{1}$ Neurological complications (ataxia, neuropathy, and tremor) have not been reported in children. The yellowish brown granular corneal deposits observed in adults treated with amiodarone $e^{4}$ occur rarely in young children and only occasionally in older children. ${ }^{15}$ Thus published reports give the impression that children are less susceptible to the unwanted effects of amiodarone.We report our experience from two centres of the use of amiodarone in children with resistant or life threatening cardiac arrhythmias.

\section{Patients and methods}

Thirty children (19 male, 11 female; age range one week to 14 years, mean seven years) were treated with amiodarone from July 1979 to October 1984. Table 1 gives details of the children grouped according to diagnosis. Nineteen children had supraventricular tachycardia (nine with electro- 
Table 1 Indications for treatment with amiodarone

\begin{tabular}{|c|c|c|c|c|c|}
\hline Arrhythmia & No & $\begin{array}{l}\text { Age at onset } \\
\text { of treatment }\end{array}$ & $\begin{array}{l}\text { Associated } \\
\text { lesions }\end{array}$ & $\begin{array}{l}\text { Duration of } \\
\text { treatment }\end{array}$ & $\begin{array}{l}\text { Previous } \\
\text { antiarrhythmic } \\
\text { medication }\end{array}$ \\
\hline $\begin{array}{l}\text { Supraventricular tachycardia } \\
\text { (proven } W-P-W)(9)\end{array}$ & $19(\mathrm{M} \mathrm{12,} \mathrm{F} \mathrm{7)}$ & 1 week-14 yr & $\begin{array}{l}\text { DORV, ASD (2), } \\
\text { VSD, P atresia }\end{array}$ & $2 \mathrm{mth}-5.3 \mathrm{yr}$ & $\begin{array}{l}\text { Digoxin (19), propranolol (8), } \\
\text { verapamil (7), disopyramide (2) }\end{array}$ \\
\hline Ventricular tachycardia & 6 (M 3, F 3) & $9-14 \mathrm{yr}$ & Cardiomyopathy & $5 \mathrm{mth}-3 \cdot 2 \mathrm{yr}$ & $\begin{array}{l}\text { Disopyramide (5), lignocaine (4), } \\
\text { mexiletine (2), digoxin (2), } \\
\text { verapamil (1) }\end{array}$ \\
\hline Atrial flutter & $4(\mathrm{M} 3, \mathrm{~F}$ 1) & 1 week-10 yr & TGA (2), VSD & 2 weeks-3.7 yr & $\begin{array}{l}\text { Digoxin (4), verapamil (3), } \\
\text { disopyramide (2) }\end{array}$ \\
\hline His bundle tachycardia & $1(\mathrm{M})$ & $1 \cdot 1 \mathrm{yr}$ & - & $1.7 \mathrm{yr}$ & $\begin{array}{l}\text { Verapamil (1), lignocaine (1), } \\
\text { disopyramide (1) }\end{array}$ \\
\hline Total & $30(\mathrm{M} \mathrm{19}, \mathrm{F} 11)$ & 1 week-14 yr & 9 & 2 weeks -5.3 yr & 29 mean ( $2 \cdot 2$ drugs/child $)$ \\
\hline
\end{tabular}

W-P-W, Wolff-Parkinson-White syndrome; DORV, double outlet right ventricle; ASD, atrial septal defect; VSD, ventricular septal defect; $P$ atresia, pulmonary atresia; TGA, transposition of greater arteries.

Numbers of patients are given in parentheses.

cardiographic or electrophysiological evidence of Wolff-Parkinson-White syndrome), four had atrial flutter, and the remaining seven children had ventricular tachycardia, which originated in the His bundle in one. Eight children had congenital structural heart disease and one had congestive cardiomyopathy. Twenty nine children had previously taken antiarrhythmic drugs (mean two drugs per child) which had been ineffective. Amiodarone was used as the first line treatment in one child with exercise related ventricular tachycardia. Two children with persistent supraventricular tachycardia received amiodarone as the second line treatment after digoxin had been ineffective.

All children received oral treatment, but five initially had intravenous amiodarone. Intravenous amiodarone $(5-7 \mathrm{mg} / \mathrm{kg}$ over 20 to 30 minutes followed by an infusion of $1-2 \mathrm{mg} / \mathrm{kg}$ for 24 to 48 hours) was given for persistent tachycardias and was followed by long term oral administration. Before the intravenous preparation became available one child received oral treatment for a persistent supraventricular tachycardia; those with paroxysmal arrhythmias were given oral treatment. The arrhythmias were documented by 12 lead electrocardiography, 24 hour electrocardiographic monitoring, or were induced by treadmill exercise testing (two patients). Seven children underwent electrophysiological testing to characterise the arrhythmia in greater detail. A favourable response to treatment was assessed by short term suppression of arrhythmias, or by suppression of symptoms during paroxysmal arrhythmias that was confirmed by 24 hour electrocardiographic monitoring or exercise testing.

All children were closely monitored for evidence of unwanted effects of treatment. Tests of thyroid function (triiodothyronine, free thryoxine, thyroid stimulating hormone) and hepatic function (aspartate transaminase, bilirubin, alkaline phosphatase) were performed at the start of treatment and every three to six months thereafter. Chest radiography was undertaken annually or more frequently if clinically indicated. Ophthalmological examination, including slit lamp examination, was performed wherever this could be achieved without a general anaesthetic (14 older children). Children and parents were questioned to determine any other possible unwanted effects including sleep disturbance or nightmares, neurological or gastrointestinal symptoms, or skin reactions. Trough plasma concentrations of amiodarone ${ }^{6}$ and its metabolite desethylamiodarone were measured when the arrhythmia was controlled and during maintenance treatment. Blood was drawn for the measurement of trough plasma concentration at least six hours after the last dose of amiodarone but in most cases the blood was drawn immediately before the next dose.

\section{Results}

Intravenous treatment with amiodarone successfully controlled the arrhythmia in all five children in whom it was used. Two children had ventricular tachycardia; the other three had supraventricular tachycardia, atrial flutter, and His bundle tachycardia. Oral amiodarone successfully suppressed the arrhythmia in 28 of the 30 children and was the only antiarrhythmic drug used in 19 of these children. In nine children the arrhythmias were suppressed by oral amiodarone in combination with other drugs. Eight children needed digoxin in addition to amiodarone and one needed amiodarone, digoxin, and verapamil to suppress arrhythmia.

Intravenous amiodarone had not been used before in the two children in whom it was ineffective. The plasma concentrations of amiodarone and desethylamiodarone and the dosage used were not 
Table 2 Oral amiodarone dosage and plasma concentrations of amiodarone and desethylamiodarone required for arrhythmia suppression and maintenance treatment. Values are means (SD)

\begin{tabular}{|c|c|c|c|c|c|c|c|c|}
\hline \multirow[b]{2}{*}{$\begin{array}{l}\text { Patients with arrhythmia } \\
\text { suppression }\end{array}$} & \multicolumn{4}{|l|}{ Amiodarone } & \multirow{2}{*}{\multicolumn{2}{|c|}{$\underset{I}{\text { Amiodarone }} \underset{M}{\left(\mathrm{mg}_{\mathrm{M}} / l\right)}$}} & \multirow{2}{*}{\multicolumn{2}{|c|}{$\begin{array}{l}\text { Desethylamiodarone } \\
(\mathrm{mg} / \mathrm{l})\end{array}$}} \\
\hline & $\begin{array}{l}\text { Dose in } m g / k \\
I\end{array}$ & $\stackrel{g}{g} /$ day & $\begin{array}{l}\text { Dose in } m g \\
I\end{array}$ & $\stackrel{2}{M} / d a y^{2}$ & & & & \\
\hline \multirow{2}{*}{$\begin{array}{l}\text { (A) All }(\mathrm{n}=28) \\
\text { (B) Age }<1 \mathrm{yr}(\mathrm{n}=11) \\
\text { (C) Age }>1 \mathrm{yr}(\mathrm{n}=17) \\
\text { Statistical difference } \\
\text { between B and C }\end{array}$} & $\begin{array}{c}10 \cdot 1(7 \cdot 6) \\
15 \cdot 3(10 \cdot 4) \\
7 \cdot 2(3 \cdot 0)\end{array}$ & $\begin{array}{l}6 \cdot 0(3 \cdot 3) \\
8 \cdot 2(4 \cdot 2) \\
4 \cdot 8(1 \cdot 7)\end{array}$ & $\begin{array}{l}224(109) \\
261(148) \\
204(77)\end{array}$ & $\begin{array}{l}175(90) \\
204(128) \\
156(51)\end{array}$ & $\begin{array}{l}0.98(0.52) \\
0.96(0.63) \\
1.02(0.46)\end{array}$ & $\begin{array}{l}0.84(0.39) \\
0.80(0.38) \\
0.96(0.38)\end{array}$ & $\begin{array}{l}0.82(0.56) \\
0.58(0.39) \\
1.01(0.59)\end{array}$ & $\begin{array}{l}0.80(0.38) \\
0.60(0.35) \\
0.95(0.30)\end{array}$ \\
\hline & $p<0.05$ & $\mathrm{p}<0.05$ & NS & NS & NS & NS & $p<0.10$ & $p<0.05$ \\
\hline
\end{tabular}

I, initial arrhythmia suppression; $M$, maintenance therapy.

significantly different from those that suppressed arrhythmia. These two children had paroxysmal orthodromic reentry atrioventricular tachycardias that were resistant to conventional treatment. Electrophysiological testing demonstrated wide atrial initiation zones for these tachycardias that have now been controlled by a combination of pre-excitation pacing ${ }^{7}$ and antiarrhythmic drugs $(\beta$ blockade was used in one and verapamil in the other).

Table 2 shows the dosages given and the plasma concentrations of amiodarone and desethylamiodarone when arrhythmia suppression was achieved and on maintenance therapy. The dosage of oral amiodarone associated with initial arrhythmia suppression ranged from 2.7 to $34 \mathrm{mg} / \mathrm{kg}$ per day (mean $10.2 \mathrm{mg} / \mathrm{kg} /$ day). The maintenance doses required (mean $6.0 \mathrm{mg} / \mathrm{kg} /$ day) were significantly lower than the dosages used initially. Higher doses (mean $15.3 \mathrm{mg} / \mathrm{kg} /$ day) were required to attain arrhythmia suppression in infants under one year of age than in older children (mean $7 \cdot 2 \mathrm{mg} / \mathrm{kg} /$ day) $(p<0.05)$; the difference in dosage between the two age groups was not significant when the dosage was calculated in terms of $\mathrm{mg} / \mathrm{m}^{2}$. Similarly, infants required higher doses during maintenance therapy when this was calculated according to body weight but not if the doses were calculated according to surface area.

The plasma concentration of amiodarone associ- ated with initial arrhythmia suppression (mean $0.98 \mathrm{mg} / \mathrm{l}$ ) was not significantly different from that achieved during maintenance treatment (mean $0.84 \mathrm{mg} / \mathrm{l}$ ), though the maintenance doses were lower than the doses used initially. The plasma concentration of amiodarone was related to the dose given, both in the initial phase (correlation coefficient $r=+0.73, p<0.001)$ and during maintenance treatment (correlation coefficient $r=+0.62, p<0.001)$. The plasma concentration of desethylamiodarone was not significantly related to the amiodarone dose either in the initial phase or during maintenance treatment. The mean plasma concentration of desethylamiodarone was significantly lower in infants during the initial phase $(0.6 \mathrm{mg} / \mathrm{l})$ and during maintenance treatment $(0.6 \mathrm{mg} / \mathrm{l})$ than in older children (initial $1.0 \mathrm{mg} / \mathrm{l}$, maintenance $1.0 \mathrm{mg} / \mathrm{l}$ ). There was no significant difference between the mean plasma concentration of amiodarone in the two age groups at either stage of treatment.

Unwanted effects were frequent (table 3). Twelve $(40 \%)$ of the 30 children developed photosensitivity. In two it was so severe, despite treatment with appropriate sun screen preparations, that amiodarone was withdrawn. The plasma concentrations of amiodarone and dosage in those with photosensitivity were not significantly higher than in other children without unwanted effects in whom arrhyth-

Table 3 Unwanted effects of amiodarone treatment in children

\begin{tabular}{|c|c|c|c|c|c|c|}
\hline \multirow[b]{2}{*}{ Unwanted effect } & \multirow[b]{2}{*}{ No } & \multirow{2}{*}{$\begin{array}{l}\text { Treatment } \\
\text { stopped }\end{array}$} & \multirow{2}{*}{$\begin{array}{l}\text { Dose of } \\
\text { amiodarone } \\
\text { (mg/kg/day) }\end{array}$} & \multicolumn{2}{|c|}{ Concentration (mg/l) } & \multirow{2}{*}{$\begin{array}{l}\text { Duration of } \\
\text { treatment } \\
\text { (mnth) }\end{array}$} \\
\hline & & & & Amiodarone & Desethylamiodarone & \\
\hline $\begin{array}{l}\text { Photosensitivity } \\
\text { Grey pigmentation } \\
\text { Sleep disturbance } \\
\text { Abnormal hepatic }\end{array}$ & $\begin{array}{r}12 \\
2 \\
4\end{array}$ & $\begin{array}{l}2 \\
1 \\
-\end{array}$ & $\begin{array}{r}6 \cdot 7 \\
7 \cdot 1 \\
11 \cdot 3\end{array}$ & $\begin{array}{l}1 \cdot 1 \\
2 \cdot 2 \\
1 \cdot 0\end{array}$ & $\begin{array}{l}1 \cdot 0 \\
2 \cdot 3 \\
0.9\end{array}$ & $\begin{array}{l}31 \\
43 \\
29\end{array}$ \\
\hline $\begin{array}{l}\text { function tests } \\
\text { Abnormal thyroid }\end{array}$ & 4 & - & $7 \cdot 5$ & 1.5 & 1.4 & 25 \\
\hline function tests & 2 & $\overline{1}$ & $\begin{array}{r}7 \cdot 5 \\
14 \cdot 0\end{array}$ & $1 \cdot 0$ & 0.9 & $\begin{array}{r}18 \\
1\end{array}$ \\
\hline Complete heart block & 1 & 1 & $\begin{array}{r}14 \cdot 0 \\
5 \cdot 7\end{array}$ & $\overline{1 \cdot 2}$ & 0.5 & $\begin{array}{r}1 \\
46\end{array}$ \\
\hline $\begin{array}{l}\text { Transient macular rash } \\
\text { Gritty eyes }\end{array}$ & & $\overline{1}$ & $\begin{array}{l}5.7 \\
3.5\end{array}$ & 0.5 & 0.9 & $\begin{array}{r}46 \\
2 \\
23\end{array}$ \\
\hline
\end{tabular}




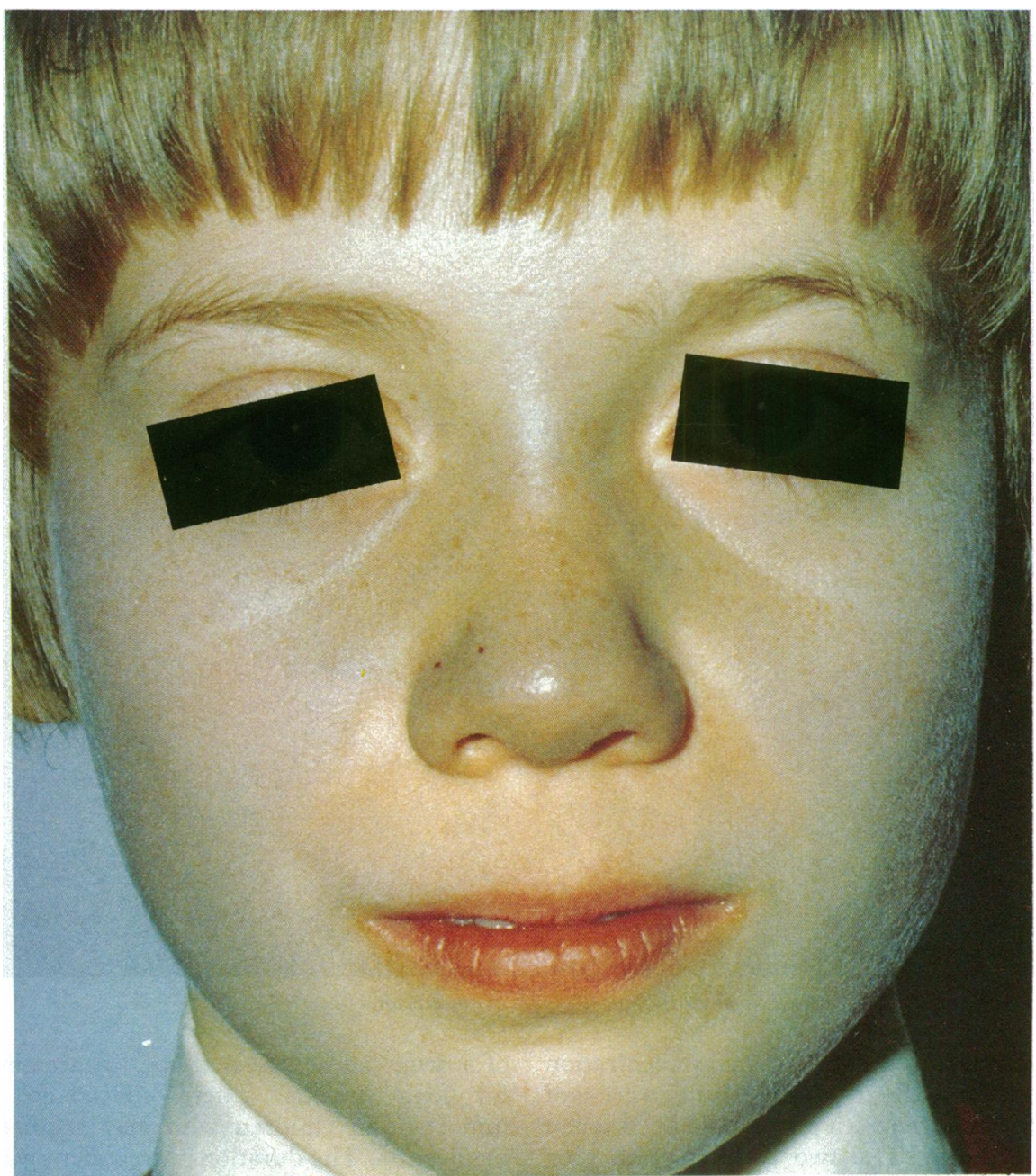

Fig 1 Grey pigmentation associated with oral amiodarone treatment.

mia suppression had been achieved. Treatment was discontinued in another child because complete heart block developed; he had first degree heart block before starting treatment. Grey facial pigmentation (fig 1) occurred in two children; in one the indication for treatment was atrial flutter and in the other it was ventricular tachyarrhythmias; both were advised to discontinue amiodarone. One patient (and his parents) preferred to continue the treatment because of the efficacy of the drug in controlling his previously resistant and life threatening atrial flutter. After 44 months of treatment with oral amiodarone he collapsed and died. The cause of death was presumed to be either a breakthrough of his tachycardia or implanted pacemaker failure. No patient developed clinical thyroid, hepatic, neurological, or pulmonary complications; however, biochemical tests of hepatic function were abnormal in four (minor increase in aspartate transaminase that was transient in two) and the thyroid function tests were abnormal in two children (raised thyroid stimulating hormone in one and raised free thyroxine in the other). Four children complained of sleep disturbance. Corneal deposits were identified in nine of 14 children who had slit lamp examination (aged seven to 14 years), and in one of these dense aggregated deposits (fig 2) persisted for 12 months after treatment was discontinued because of grey pigmentation. One child complained of gritty eyes but no ophthalmological abnormality could be detected; the symptoms were so severe that treatment was discontinued and this symptom disappeared. Treatment was stopped because of unwanted effects in a total of five patients. 


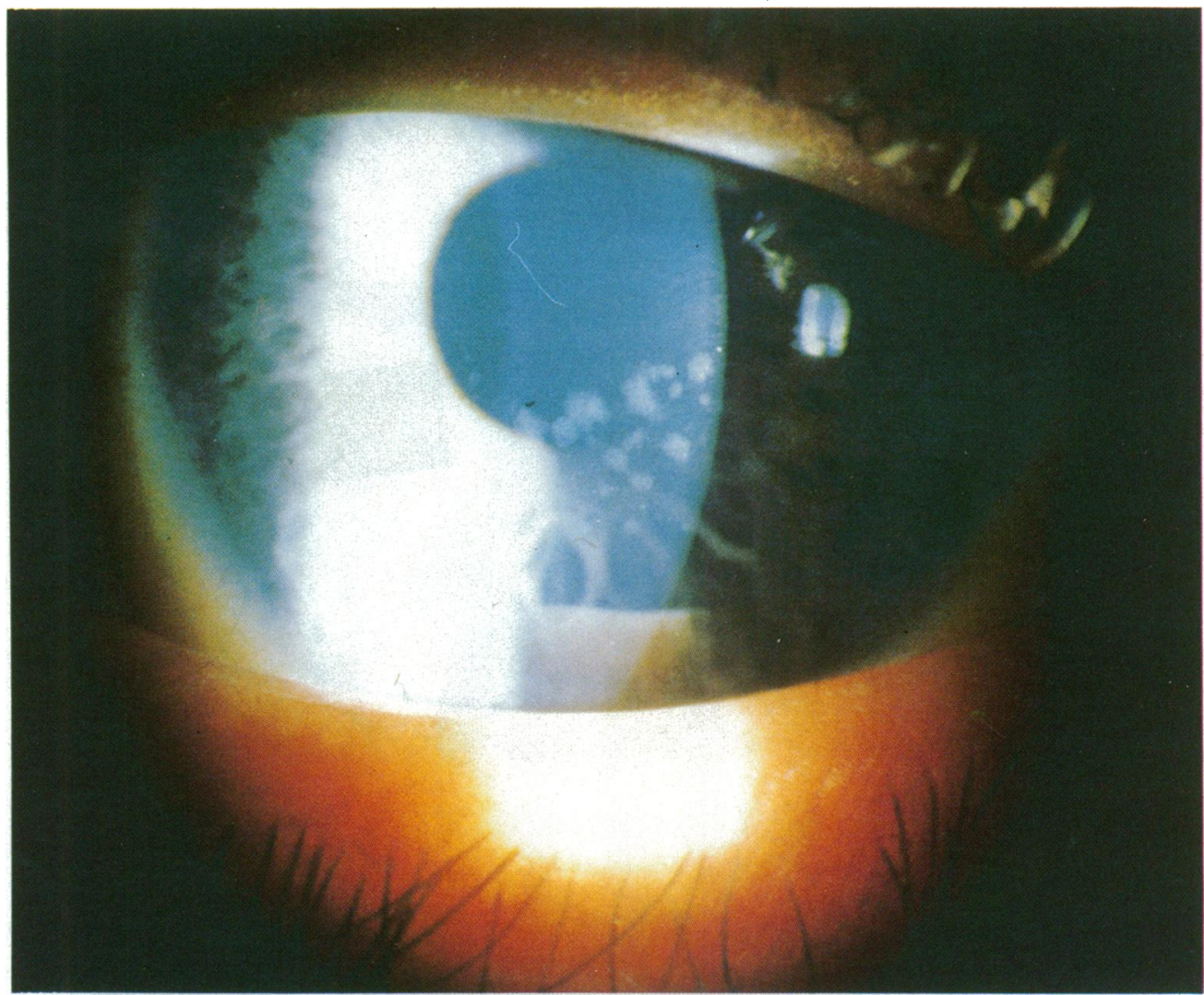

Fig 2 Dense aggregated corneal deposits seen on slit lamp examination.

The amiodarone dosage and plasma concentration of amiodarone and desethylamiodarone were not higher in those children with unwanted effects when analysed as a group. The two children with grey pigmentation had both required high doses of amiodarone during both initial and long term maintenance treatment and had high plasma concentrations of amiodarone over a prolonged period. The four children with sleep disturbance also required high doses of amiodarone during maintenance treatment. The plasma concentration of amiodarone, however, was not high in this group. The plasma concentrations of amiodarone and desthylamiodarone were high in the four children who developed biochemical evidence of hepatic dysfunction. Because the numbers with grey pigmentation, sleep disturbance, and biochemical hepatic dysfunction were small, statistical analysis of the differences in dose or plasma concentration was not possible.

\section{Discussion}

The efficacy and true incidence of unwanted effects of a drug can be assessed only by treating patients for long periods. These effects are especially important in children who may require life long medication. The duration of treatment was longer in this study than in two previously reported large studies of the use of amiodarone in children. ${ }^{18}$ Coumel and Fidelle studied 135 children treated with amiodarone for an average of five months ${ }^{1}$ and Garson et al reported 39 young patients (age range six weeks to 30 years) treated for an average of 17 months. ${ }^{8}$ In our group of patients, all of whom were aged $<15$ years, the average duration of treatment was 23 months and only one was treated for < two months.

Amiodarone was effective (alone in $63 \%$ and in combination with other treatment in $30 \%$ ) in suppressing resistant or life threatening cardiac arrhythmias in 28 children but was ineffective for arrhythmias in two patients with Wolff-ParkinsonWhite syndrome. These latter two children had incessant repetitive reentry tachycardias that subsequently proved to be particularly difficult to control with other antiarrhythmic drugs and pacing. 
Table 4 Efficacy of amiodarone in children

\begin{tabular}{lrlll}
\hline Study & No & $\begin{array}{l}\text { Complete } \\
\text { control } \\
(\%)\end{array}$ & $\begin{array}{l}\text { Partial } \\
\text { control } \\
(\%)\end{array}$ & $\begin{array}{l}\text { Failure } \\
(\%)\end{array}$ \\
\hline $\begin{array}{l}\text { Present study } \\
\text { Coumel and }\end{array}$ & 30 & 63 & 30 & 7 \\
$\begin{array}{l}\text { Fidelle } \\
\text { Garson } \text { et al }^{8}\end{array}$ & 135 & 60 & 33 & 7 \\
\hline
\end{tabular}

The efficacy of amiodarone demonstrated in our study was almost identical with that found by Coumel and Fidelle (table 4). Shahar et al recently reported $100 \%$ success with amiodarone for the treatment of supraventricular tachycardia associated with Wolff-Parkinson-White syndrome ${ }^{9}$; this does not accord with our experience.

The weight of a child is often used to calculate the dose $(\mathrm{mg} / \mathrm{kg} /$ day $)$ and this may lead to an ineffective dose of amiodarone being prescribed for infants. The plasma concentration of amiodarone associated with arrhythmia suppression was similar in infants and older children, but the dose required to achieve arrhythmia suppression when calculated according to weight $(\mathrm{mg} / \mathrm{kg} /$ day) was higher in the infant group than in those aged over one year. Dosages calculated on the basis of surface area were not significantly higher in the infant group. The plasma concentration of amiodarone associated with arrhythmia suppression was similar in the infant and older age groups but the plasma concentration of desethylamiodarone associated with arrhythmia suppression was significantly lower in the infant group; this may have been the result of a more rapid excretion or reduced production of the metabolite in infants. In children, as in adults, there was a correlation between the dose and the plasma concentration of amiodarone. ${ }^{10}$ In contrast there was no such correlation between the dose of amiodarone and the plasma concentration of the metabolite desethylamiodarone.

Amiodarone can be given either intravenously or orally; unwanted cardiovascular effects are more commonly reported after intravenous administration. In all age groups potentially serious cardiovascular complications, such as atrioventricular block, hypotension, or shock, may occur after intravenous amiodarone. ${ }^{11}$ In contrast the oral administration of amiodarone in children has been reported to be relatively free from adverse effects, even in those with cardiomegaly and congestive heart failure. ${ }^{1}$

We report a high incidence of skin photosensitivity, grey pigmentation, and corneal deposits in children on amiodarone; this was similar to that found in adults. ${ }^{23}$ Garson et al reported an $8 \%$ inci- dence of skin photosensitivity ${ }^{8}$ and in the study by Coumel and Fidelle five of 135 children developed skin photosensitivity. ${ }^{1}$ In our study $40 \%$ of patients showed skin photosensitivity. This may reflect climatic or racial differences in the populations studied. All patients in our study were white. Grey pigmentation may be related to a high cumulative dose of amiodarone. ${ }^{2}$ One child in the study by Coumel and Fidelle received treatment for 72 months before developing grey pigmentation (dose unspecified ${ }^{1}$; both of the children in our study who developed skin pigmentation had received amiodarone treatment for longer than 30 months and had required high doses which were associated with high plasma concentrations of amiodarone and desethylamiodarone. Corneal microdeposits were reported to occur in children over 10 years of age, but three of our patients with corneal deposits were aged $<10$ years. No child aged $<$ four years was examined by slit lamp but $64 \%$ of those in whom this examination was performed had corneal deposits. This was more than has been found in previous studies. These corneal deposits have been reported to resolve within seven months after the end of treatment, ${ }^{4}$ but one of the children in our study had unusually dense aggregated deposits which persisted for 12 months after treatment was discontinued.

The frequency of other unwanted effects found in this study resembled that in previous studies. Coumel and Fidelle reported clinical thyroid dysfunction in three children, and personality change, nightmares, or hallucinations in four children. ${ }^{1}$ We did not observe any personality change in our patients; however, four did complain of sleep disturbance. The dosage of amiodarone required for maintenance in these four children was higher, but not significantly so, than that required in other children, but the plasma concentrations of amiodarone and its metabolite were not higher. None of the patients reported by Coumel and Fidelle developed bradycardia, ${ }^{1}$ whereas in the study by Garson et al four patients, all with atrial flutter, developed severe bradycardia. ${ }^{8}$ In our study one child with atrial flutter developed complete heart block; he had first degree heart block before starting amiodarone. Although there has been one report of the development of torsade de pointe in a child receiving amiodarone, ${ }^{12}$ this was not found in our study or in the other two large studies.

Unwanted effects were more common than had been previously reported in this age group, but group analysis showed that the occurrence of the unwanted effects was unrelated to the dose, duration of treatment, or plasma concentration of amiodarone. Few major adverse effects thought to be related to amiodarone dose were encountered, other 
284

than skin pigmentation and biochemical hepatic dysfunction (there were no cases involving pulmonary complications, clinical hepatic dysfunction, neuropathy, or myopathy). Plasma concentrations of amiodarone in the two children with grey pigmentation and the four children with biochemical hepatic dysfunction were high, and those with pigmentation and sleep disturbance were receiving higher maintenance doses of amiodarone than those who were unaffected.

We conclude that amiodarone is an effective antiarrhythmic drug in childhood but that its use should be reserved for those with resistant life threatening arrhythmias. Particular care should be taken with infants for whom a higher weight related oral dose is required to achieve arrhythmia suppression. We suggest that oral doses should be calculated on the basis of surface area. Arrhythmia control is associated with a wide range of plasma concentrations of amiodarone and more data are needed to investigate the clinical value of plasma measurements as a guide to avoiding serious adverse effects.

\section{References}

1 Coumel PL, Fidelle J. Amiodarone in the treatment of cardiac arrhythmias in children: one hundred thirtyfive cases. Am Heart f 1980;100:1063-9.

2 Harris L, McKenna WJ, Rowland E, Holt DW, Storey
Bucknall, Keeton, Curry, Tynan, Sutherland, Holt

GCA, Krikler DM. Side-effects of long-term amiodarone therapy. Circulation 1983;67:45-51.

3 McGovern B, Garan H, Kelly E, Ruskin JN. Adverse reactions observed during treatment with amiodarone hydrochloride. $\mathrm{Br}$ Med $\mathcal{f}$ 1983;287:175-80.

4 Ingram DV. Ocular effects in long-term amiodarone therapy. Am Heart $f$ 1983;106:902-5.

5 Rosenbaum MB, Chiale PA, Halpern MS, et al. Clinical efficacy of amiodarone as an antiarrhythmic agent. Am $\mathcal{F}$ Cardiol 1976;38:934-44.

6 Storey GCA, Holt P, Curry PVL, Holt DW. Highperformance liquid chromatographic measurement of amiodarone and its desethyl metabolite: methodology and preliminary observations. Ther Drug Monit 1982;4:385-8.

7 Davies DW, Bucknall CA, Curry PVL. Prophylactic antitachycardia pacemaker: permanent pre-excitation [Abstract]. Br Heart $\mathcal{F}$ 1984;51:104.

8 Garson A Jr, Gillette PC, McVey P, et al. Amiodarone treatment of critical arrhythmias in children and young adults. $\mathcal{A} \mathrm{Am}$ Coll Cardiol 1984;4:749-55.

9 Shahar E, Barzilay Z, Frand M, Feigl A. Amiodarone in control of sustained tachyarrhythmias in children with Wolff-Parkinson-White syndrome. Pediatrics 1983;72:813-6.

10 Holt DW, Tucker GT, Jackson PR. Amiodarone pharmacokinetics. Am Heart f 1983;106:840-7.

11 Marcus FI, Fontaine GH, Frank R, Grosgogeat Y. Clinical pharmacology and therapeutic applications of the antiarrhythmic agent, amiodarone. Am Heart $\mathcal{F}$ 1981;101:480-93.

12 Hesslein PS, Costigan DC, Koren G, et al. Oral amiodarone therapy in childhood: early experience [Abstract]. Pediatr Cardiol 1983;4:313. 